\title{
Ground Beetle (Coleoptera: Carabidae) Assemblages and Slug Abundance in Agricultural Fields Under Organic and Low-Input Conventional Management Within a Long-Term Agronomic Trial in Central Italy
}

\author{
Elisabetta Rossi, ${ }^{1,3, \odot}$ Daniele Antichi, ${ }^{2, \bullet}$ Augusto Loni, ${ }^{1}$ Roberto Canovai, ${ }^{1}$ \\ Massimo Sbrana, ${ }^{2}$ and Marco Mazzoncini ${ }^{2}$ \\ ${ }^{1}$ DAFE Department of Agriculture, Food and Environment, University of Pisa, Via del Borghetto, 80, 56124 Pisa, Italy, ${ }^{2}$ CiRAA Centre for \\ Agri-environmental Research ‘Enrico Avanzi’, via Vecchia di Marina, 6, 56122 San Piero a Grado, Pisa, Italy, and ${ }^{3}$ Corresponding author, \\ e-mail: elisabetta.rossi@unipi.it
}

Subject Editor: Richard Redak

Received 10 April 2019; Editorial decision 12 September 2019

\begin{abstract}
Inside a long-term agronomic trial aimed at evaluating the effects of organic and low-input conventional management systems on soil fertility and arable crop production, we selected six fields bordered by hedgerows, three under each management system. Here, we analyzed the carabid assemblages and the slug abundance. Samplings took place in five different periods, across $1 \mathrm{yr}$ of observations. The carabid abundances were similar in organic and conventional fields. The Shannon-Wiener diversity index $\left(H^{\prime}\right)$ showed a higher value in the conventional fields, although in the organic fields, a higher number of species were observed. The multivariate analysis described similar carabid communities, but excluding the period factor, it showed a significant influence of the management system. There was no difference between the captures of traps placed along the hedgerow and in the middle, whereas in the conventional fields, the hedgerow traps captured a higher number of specimens, showing a role of the hedgerow as carabid reservoir. The slugs were present mainly while green manure was grown on the organic fields where also Poecilus cupreus Linné, 1758 (Coleoptera: Carabidae) was captured abundantly.
\end{abstract}

Key words: Carabid, community, agricultural management system, hedgerow, biodiversity

Carabids are efficient bioindicators in terrestrial ecosystems because of their adaptability and ability to colonize almost all terrestrial habitats and geographical locations, their quick response to environmental changes, the ease in collecting them, and their relatively stable taxonomy. They are also useful organisms in agroecosystems due to their role as predators of crop insect pests (Kotze et al. 2011, Pizzolotto et al. 2018) and slugs, thus reducing their populations (Fusser et al. 2016).

However, the risk of misusing data on carabid assemblages as environmental indicators has been stressed (Gobbi and Fontaneto 2008) when considering only species richness without a contextualization of their ecological role.

In temperate areas, the differences among carabid communities are frequently used as an indicator in the evaluation of the impact caused by different agricultural practices, crops, and surrounding habitats (Holland and Luff 2000, Albertini et al. 2017, Lemic et al. 2017). However, carabid populations seem to be relatively constant over time (Holland 2002) in arable crops, as shown from the data obtained in long-term trials carried out in arable fields (Luff 1982). Habitat diversification within cultivated fields can significantly influence the quantity and quality of carabid fauna in agroecosystems. Field margins and their management as well as agroecological infrastructures have an influence on the qualitative and quantitative composition of carabid populations; thus, edges can be an important tool for carabid conservation (Rouabah et al. 2015). The presence of hedgerows, in particular, is known to affect the diversity and distribution of Carabids, as some species are typically related to the hedges, whereas others prefer the cropped areas, have a weak preference for the hedge habitat, or are randomly distributed between the field and the hedge (Fournier and Loreau 1999).

Carabids have frequently been used to compare the biodiversity in organic and conventional management systems (Kromp 1989, Purtauf et al. 2005, Gomiero et al. 2011, Legrand et al. 2011). Much evidence shows how agroecological practices can mean that organic systems have less of an impact on carabid habitats than conventional ones. 
Some soil management practices such as reduced tillage (with or without soil inversion; Shearin et al. 2007) or cover cropping (Shearin et al.2008) can considerably influence the effects of organic management on carabid biodiversity. Normally, low-input practices make organic systems overall more eco-friendly and sustainable than conventional ones, although the sustainability is important not only from a short-term perspective, but also taking into account a long timeline. In this view, long-term trials, despite the investment in manpower, help us to understand the ecology of agricultural systems. Carabids can be a useful tool to monitor the effects of different management systems also in long-term trials (Legrand et al. 2011).

Carabids are active generalist predators of slugs, which could represent an important resource in their diet (Bohan et al. 2000). Terrestrial slugs live worldwide in temperate and tropical regions. Some species are important agricultural pests in Europe, North America, New Zealand, some parts of Australia and Central America (Howlett 2012). Mild and damp climate, but also agronomic practices as no-tillage (Douglas and Tooker 2012), herbaceous field borders (Fusser et al. 2016), the overwintering green crops, or organic management (Vernava et al. 2004) can significantly promote infestations.

Little information is known about the economic importance of slugs as crop pests in Italy, but their damage is reported on many crops (Santini 2000).

This article describes the carabid assemblages and the slug abundance monitored in six experimental fields as part of a long-term agronomic trial $15 \mathrm{yr}$ after it started. The fields were all in the same size with a hedgerow on one side and managed under two different systems (organic and conventional management). This situation is interesting due to the contiguity of the fields and the length of the management systems.

The focus was on the following hypotheses:

1) the carabid community structures will differ under the two management systems;

2) the hedgerows have a different role in carabid distribution depending on the presence of an overwintering cover crop in organic fields or bare soil in the conventional fields; and

3) there is a relationship between the slug abundance and the carabid assemblages.

\section{Materials and Methods}

\section{MASCOT Long-Term Trial-Experimental Site}

Since 2001, the Centre for Agri-environmental Research 'E. Avanzi' (CiRAA), S. Piero a Grado, Pisa, Italy (latitude $43^{\circ} 40^{\prime} \mathrm{N}$, longitude $10^{\circ} 18^{\prime} \mathrm{E}$ ) hosts the MASCOT (Mediterranean Arable Systems COmparison Trial) trial (Barberi and Mazzoncini 2006), a long-term experiment still ongoing, focusing on the comparison of organic and conventional management systems.

Its main objective is to compare soil fertility (in the broader sense of term), crop performance, and agroecological aspects for a 5 -yr stockless arable crop rotation under organic and a low-input conventional management system. The crop rotation included maize (Zea mays L.), common wheat (Triticum aestivum L.), sunflower (Helianthus annuus L.), pigeon bean (Vicia faba var. minor Beck), and durum wheat (Triticum turgidum subsp. durum Desf.). In the organic system, green manures were winter grown in between winter wheat and spring crops (i.e., maize and sunflower; Ciaccia et al. 2017). The fields in the organic system were supplied with commercial organic fertilizers (i.e., pelleted dried staple manure), whereas the conventional fields were supplied with mineral fertilizers. The weed control was mechanical in the organic system (flextine harrowing and inter-row cultivation) and chemical/mechanical (inter-row cultivation for row crops) in the conventional system. The main and secondary tillage methods were the same for both systems (Mazzoncini et al. 2010, 2015).

CiRAA fields are included in the Migliarino San Rossore Massaciuccoli Park territory and classified as transition areas of the UNESCO Biosphere Reserve 'Selva Pisana'. This location imposes a low-input agriculture also in the conventional system.

\section{Experimental Fields and Their Management}

Six rectangular experimental fields were chosen among the plots of the MASCOT trial (Fig. 1). Their sizes were about $30 \times 300 \mathrm{~m}$ each one, and they were delimited by a hedgerow and a ditch along the longest sides. Three were under organic management and three were under conventional management. The hedges contained a mixture of local species: Crataegus monogyna Jacq., Cornus sanguinea L., Ligustrum vulgare L., Lonicera xylosteum L., Prunus spinosa L., and Rhamnus cathartica L. and were about $1.5 \mathrm{~m}$ deep. In the 2015/2016 season, in the organic fields, a mixture of hairy vetch (Vicia villosa Roth.) and barley (Hordeum vulgaris L.) was grown as green manure between September 2015 and April 2016. The conventional fields, on the other hand, were kept bare until the following spring. Seedbeds were prepared for maize in the two systems by two passes of a rotary harrow on 28 April and 5 May 2016, respectively. In the conventional fields, one spray of glyphosate $(900 \mathrm{~g} / \mathrm{ha}$ of active ingredient) was performed on 28 April to reduce the number of weeds that had grown over the winter. In Table 1, the sequence of crops in organic and conventional fields is shown.

Across the sampling periods until the beginning of July 2016, the fields bordering the other sides of the hedgerows were cropped with common wheat in organic or conventional system. In the period from wheat harvest (4 July 2016) to September 2016, these fields were kept bare (with wheat residues retained on soil surface) and untilled.

\section{Animal Sampling \\ Carabids}

Carabids were sampled by pitfall traps consisting of plastic 250-ml jars, which were buried up to the opening, and covered with a plastic dish, supported by four aluminum sticks and $5 \mathrm{~cm}$ high from the trap border. Each trap was baited with $100 \mathrm{ml}$ of white vinegar and $10 \mathrm{~g}$ of $\mathrm{NaCl}$. Sixteen traps were placed in two parallel rows (eight traps per row) about $15 \mathrm{~m}$ from each other along the median axis of the field and along the edge, tangential to the hedgerows. The trap distance along the row was $30 \mathrm{~m}$ (Fig. 1). The samplings covered a period of 10 mo from 6 November 2015 to 12 September 2016 . This interval was ranked in five different periods, as indicated in Table 1: each period included 2 or 4 wk of sampling. The five periods were chosen according to the crop development, focusing on the periods with likely higher presence of carabids and slugs and with contrasting weather conditions to have a realistic representation of the population dynamics across the year. The first period was set around the sowing and establishment of the green manure mixture sown in the organic fields. The second period covered $2 \mathrm{wk}$ before the termination date of the green manure mixture in the organic system. The third, fourth, and fifth periods covered, respectively, early establishment, vegetative growth, and harvest time of the corn crop following the green manure mixture in the organic fields and the bare soil in the conventional fields. 

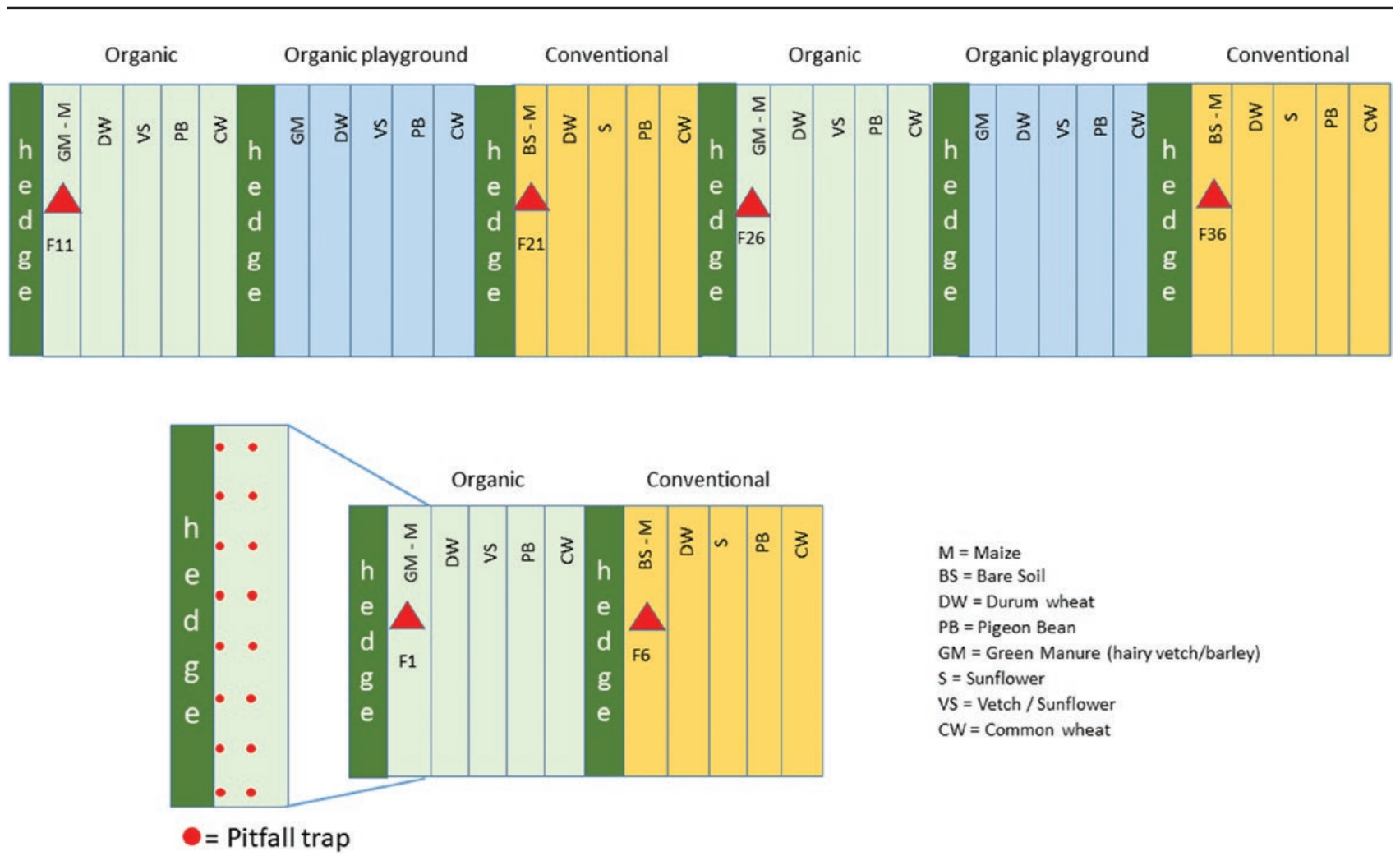

Fig. 1. Field arrangement of MASCOT trial. Triangles show the experimental fields where the pitfall and mat traps were placed. For each field that is not part of our experiment, the main crop during the sampling periods of carabids and slugs is indicated. Label GM-M indicates the rotation of green manure and maize in organic fields, whereas BS-M indicates the bare soil before maize, in conventional fields. Dots in detail indicate the position of pitfall traps.

Table 1. Sampling dates and crops grown in the experimental fields

\begin{tabular}{|c|c|c|c|c|}
\hline \multirow[t]{2}{*}{ Week of sampling } & \multirow[t]{2}{*}{ Periods } & \multirow[t]{2}{*}{ Sampling dates } & \multicolumn{2}{|c|}{ Management } \\
\hline & & & Organic & Conventional \\
\hline 1 & 1 & 6 Nov. 2015 & Barley and vetch & Bare \\
\hline 2 & & 13 Nov. 2015 & Barley and vetch & Bare \\
\hline 3 & & 19 Nov. 2015 & Barley and vetch & Bare \\
\hline 4 & & 27 Nov. 2015 & Barley and vetch & Bare \\
\hline 5 & 2 & 4 Apr. 2016 & Barley and vetch & Bare \\
\hline 6 & & 11 Apr. 2016 & Barley and vetch & Bare \\
\hline 7 & 3 & 25 May 2016 & Corn & Corn \\
\hline 8 & & 8 June 2016 & Corn & Corn \\
\hline 9 & 4 & 4 July 2016 & Corn & Corn \\
\hline 10 & & 11 July 2016 & Corn & Corn \\
\hline 11 & & 25 July 2016 & Corn & Corn \\
\hline 12 & & 1 Aug. 2016 & Corn & Corn \\
\hline 13 & 5 & 5 Sept. 2016 & Corn & Corn \\
\hline 14 & & 12 Sept. 2016 & Corn & Corn \\
\hline
\end{tabular}

The trap content was removed after $2 \mathrm{~d}$ and sieved; the carabids were collected and stored in $70 \%$ alcohol until their classification. Carabids were identified to species level with the specific keys for Italian carabids (Brandmayr et al. 2005; Pesarini and Monzini 2010, 2011). Specimens were stored in the Department of Agriculture, Food and Environment (DAFE) entomological collection.

Slugs

Slug samplings were performed with eight commercial mat traps (Anti-Limaces Ciblage, De Sangosse) aligned in the middle of each experimental field, adjacent to the pitfall traps to maximize any abundance difference between organic and conventional fields, assuming that close to the hedgerows the habitats were more similar. We were more interested in studying the abundance of slugs in relationship to carabids as their potential predators than describing their community structure so that the classification was carried out at family level without distinguishing between young and mature individuals. A trap was made with a multi-layer material, with aluminum on one side and absorbent tissue on the other $\left(0.25 \mathrm{~m}^{2}\right.$ surface, $0.5 \times 0.5 \mathrm{~m}$ size). This design allows the trap to keep water beneath (i.e., in the absorbent tissue facing downwards) and reflect solar radiation on top (i.e., on aluminum side facing upwards), thus preventing air temperature rising so high to kill or deter slugs using the traps as shelter along the day. The mat traps were soaked in 
water for half an hour before being installed in the field. The traps were removed from the ground after $48 \mathrm{~h}$ at the same time of pitfall emptying and the slugs sheltering under the mat traps were collected in plastic jars and then counted and classified in the lab at the family level following the key of Cameron et al. (1983). The captures were relevant only in organic fields. Here during the periods in which the slugs were captured, a correlation analysis was performed between the slug abundance and that of the whole captures of carabids. This same analysis was repeated selecting the most represented carabid species. The analysis was performed using the 'agricolae' package for R (Mendiburu 2015).

\section{Estimate of Carabid Biodiversity}

Data on captures were used to estimate biodiversity under the two management systems. The species richness was calculated using the two nonparametric estimators Chao 1 and $\mathrm{Chao} 2$ in data sets from the organic and conventional fields. Chao1 is one of the most effective abundance-based estimators, basing its calculations firstly on singletons and doubletons, i.e., the number of species represented for just one or two individuals across all the samples (Basualdo 2011). Chao2 is the corresponding incidence-based estimator, counting singles and duplicates, i.e., species that are present only in one or two samples, respectively (Chao and Chiu 2016). The Shannon-Wiener diversity $\left(H^{\prime}\right)$ and Pielou's evenness $\left(J^{\prime}\right)$ indexes were calculated considering all the captures for the organic and conventional fields (Magurran 1988).

\section{Statistical Analysis \\ Multivariate Analysis}

Data on carabid captures were organized into a raw data matrix with all samples in columns, and species and their relative abundance in rows. A similarity matrix was created calculating the Bray-Curtis similarity index between each pair of samples. A two-dimensional graphical representation, i.e., the nonmetric multidimensional scale (NMDS), was performed on this similarity matrix and the null hypothesis (i.e., no differences exist among the groups of carabid population samples) was tested by the nonparametric permutational, multivariate analysis of variance (Permanova). We verified the homogeneity of the data dispersion by the permutational analysis of data dispersion (Permdisp).

We adopted two different experimental designs. In the first one, a mixed design with three factors, 'Management' (Mn; fixed factor with two levels, Organic, Org, and Conventional, Con), 'Trap position' (Tp; fixed factor with two levels, Edge, Ed, or Middle of the field, Md), and the random factor 'Period' (Pe; with five levels, 1-5), was adopted. The second was a crossed design with a two-fixed factors, Mn (two levels, Org and Con) and Tp, (two levels, Ed or Md). We collapsed the time factor by cumulating all sampling dates to obtain a final, global view of the influence of management and trap position on the carabid community structure. A $P$ value of 0.01 was chosen as the significance level.

We also performed an analysis of the similarity percentage of species contribution (SIMPER) considering the two experimental designs (Clarke and Warwick 2001). In conventional fields, the analysis was performed for highlighting the species mostly contributing to the dissimilarity between the groups Con-Md and Con-Ed.

Permanova A+ for Primer software package was used for all analyses (Anderson et al. 2008).

Chi-Square

\section{Comparison}

The comparison among the capture abundances was carried out using the interactive calculation tool for chi-square tests of goodness of fit and independence (Preacher 2001).

\section{Results}

\section{Carabids}

During the trial, the traps captured 14,507 carabids in total, with 7,319 specimens captured in the organically managed fields and 7,188 in the conventional ones (Table 2). The differences between the two abundances were not statistically different $\left(\chi^{2}=1.18 ; \mathrm{df}=1 ; P=0.28\right)$. The captures were higher the second, fourth, and fifth periods, despite the fourth and fifth periods consisted of only two sampling weeks. There were a total of 54 species, 48 from the organic fields and 44 from the conventional ones. The majority of captured species were zoophagous and macropterous. The species with the highest captures were Poecilus

Table 2. Total number of Carabids trapped in the organic and conventional fields during the sampling dates

\begin{tabular}{|c|c|c|c|c|c|c|c|}
\hline \multirow[t]{3}{*}{ Sampling periods } & \multirow[t]{3}{*}{ Sampling dates } & \multicolumn{3}{|c|}{ Capture number } & \multicolumn{3}{|c|}{ Species number } \\
\hline & & \multicolumn{2}{|c|}{ Management } & \multirow[t]{2}{*}{ Tot. no. } & \multicolumn{2}{|c|}{ Management } & \multirow[t]{2}{*}{ Tot. no. } \\
\hline & & Org & Con & & Org & Con & \\
\hline \multirow[t]{4}{*}{1} & 6 Nov. 2015 & 227 & 247 & 474 & 20 & 23 & 30 \\
\hline & 13 Nov. 2015 & 90 & 83 & 173 & 11 & 11 & 17 \\
\hline & 19 Nov. 2015 & 107 & 62 & 169 & 16 & 9 & 17 \\
\hline & 27 Nov. 2015 & 79 & 10 & 89 & 8 & 4 & 8 \\
\hline \multirow[t]{2}{*}{2} & 4 Apr. 2016 & 1,586 & 297 & 1,883 & 17 & 20 & 23 \\
\hline & 11 Apr. 2016 & 538 & 560 & 1,098 & 11 & 18 & 19 \\
\hline \multirow[t]{2}{*}{3} & 25 May 2016 & 158 & 592 & 750 & 12 & 17 & 20 \\
\hline & 8 June 2016 & 459 & 113 & 572 & 19 & 11 & 23 \\
\hline \multirow[t]{4}{*}{4} & 4 July 2016 & 274 & 203 & 477 & 17 & 14 & 20 \\
\hline & 11 July 2016 & 423 & 389 & 812 & 16 & 18 & 23 \\
\hline & 25 July 2016 & 911 & 671 & 1,582 & 19 & 18 & 22 \\
\hline & 1 Aug. 2016 & 839 & 1,166 & 2,005 & 15 & 17 & 21 \\
\hline \multirow[t]{3}{*}{5} & 5 Sept. 2016 & 1,052 & 1,895 & 2,947 & 15 & 15 & 17 \\
\hline & 12 Sept. 2016 & 576 & 900 & 1,476 & 13 & 15 & 16 \\
\hline & Tot. no. & $7,188 \mathrm{a}$ & $7,319 \mathrm{a}$ & 14,507 & 48 & 44 & 54 \\
\hline
\end{tabular}

Same letters represent not significant differences $\left(\chi^{2}=1.18 ; \mathrm{df}=1 ; P=0.28\right)$. 
cupreus (Linnaeus), followed by Pseudoophonus rufipes (De Geer), Brachinus immaculicornis Dejean and Pterostichus melas Dejean, respectively. Poecilus cupreus and P. rufipes accounted for $52 \%$ of total captures (Supp Table 1 [online only]).

Table 3 shows the captures of these two species divided for the sampling period and trap position factors. The captures of $P$. cupreus in the border traps and those in the middle were significantly different $\left(\chi^{2}=987.2 ; \mathrm{df}=1 ; P<0.001\right)$ in both organic and conventional fields. Poecilus cupreus was particularly abundant in the second sampling period and in the middle traps of organic fields.

For $P$. rufipes, the difference between the captures in the edge and middle traps was significantly different $\left(\chi^{2}=42.9 ; \mathrm{df}=1 ; P<0.001\right)$ only in conventional fields, with a higher number of specimens trapped on the edge and a peak in the fifth period of sampling.

\section{Estimate of Carabid Biodiversity}

Both the Shannon-Wiener diversity and the Pielou's evenness indexes were lower in the organic than the conventional fields $\left(H^{\prime}=1.834\right.$ vs 2.066 and $J^{\prime}=0.471$ vs 0.546 , respectively) even if the total number of species (49 vs 44$)$ and specimens $(7,319$ vs 7,188$)$ were higher in the organic fields.

These data matched consistently with the lower evenness measured for the organic fields than the conventional ones. This might be reasonable due to the population peak of $P$. cupreus during the second period of samplings (Table 3), which produced an unbalanced evenness of this species. For this reason, we calculated the diversity indexes without considering $P$. cupreus (Supp Table 2 [online only]), showing that both diversity indexes were higher in organic than in conventional fields.

\section{Carabid Species Richness Estimators}

Nonparametric estimators Chao1 and Chao 2 reached an asymptote in both organic and conventional fields, with a different number of estimated species. In the organic fields, a higher number of species is expected than in the conventional fields (62 vs 52 ). However, in both management options, the number of species observed was lower than the estimated ones: this suggests that a higher number of species could be hosted both in organic and conventional fields (Fig. 2A and B).

\section{Multivariate Analysis}

Three-Factor Experimental Design

In the graph of the NMDS analysis, the samples organized on the basis of the $\mathrm{Mn}$ and $\mathrm{Tp}$ factors were not grouped into different clusters (Fig. 3A). In contrast, taking into account the Pe factor, ordination showed definite clouds of data corresponding to the five sampling periods (Fig. 3B).

The sample distribution described by the NMDS analysis was supported by the Permanova, which found no significant differences between groups of samples on the basis of the $\mathrm{Mn}$ factor $(P=0.0192, \mathrm{df}=1$, Unique perms. $=9,926)$ and the Tp factor $(P=0.6851, \mathrm{df}=1$, Unique perms. $=9,943)$, without significant interaction $\mathrm{Mn} \times \mathrm{Tp}(P=0.1922, \mathrm{df}=1$, Unique perms. $=9,954)$. However, highly significant differences were found for the Pe factor $(P=0.0001, \mathrm{df}=4$, Unique perms. $=9,891)$. An analysis of the dispersion of samples confirmed the homogeneous dispersion of samples, without influencing the Permanova results $(F=0.42276$; $\mathrm{df}=1 ; \mathrm{df} 2=422 ; P($ perm $)=0.574)$. The Pe factor produced the highest significance value between groups, also determining a strong influence on the interactions with other factors $(\mathbf{M n} \times$ Pe $P=0.0001, \mathrm{df}=4$, Unique perms. $=9,977 ; \mathrm{Tp} \times \mathrm{Pe} P=0.0001$, $\mathrm{df}=4$, Unique perms. $=9,886 ; \mathrm{Mn} \times \mathrm{Tp} \times \operatorname{Pe} P=0.0001, \mathrm{df}=4$, Unique perms. $=9,891)$. Given that $\mathrm{Pe}$ is a random factor, we only considered its contribution to the variation among samples excluding the residuals (Supp Table 3 [online only]). We also applied Permanova to analyze separately the captures of the first two periods and those of the last three periods of sampling. This is because in the first two sampling periods, the crops in the conventional and organic fields were not identical (due to the particular features of the cropping system: green manure crop in organic fields vs bare soil in conventional fields). The results are reported in Supp Tables S4 and S5, where Pe factor was the only significant factor, whereas $\mathrm{Mn}$ and $\mathrm{Tp}$ factors were not significant.

\section{Two-Factor Experimental Design}

The NMDS analysis performed on a two-factor design and based on the Mn factor, produced two clouds of data with the samples of the organic fields grouped on the upper-left of the graph, and the

Table 3. Captures of Poecilus cupreus and Pseudoophonus rufipes divided according to trap position (edge or middle) in the sampling period and under the organic and conventional management systems

\begin{tabular}{|c|c|c|c|c|c|c|c|c|c|}
\hline \multirow[t]{3}{*}{ Sampling periods } & \multirow[t]{3}{*}{ Sampling dates } & \multicolumn{4}{|c|}{ Poecilus cupreus } & \multicolumn{4}{|c|}{ Pseudoophonus rufipes } \\
\hline & & \multicolumn{2}{|c|}{ Org. } & \multicolumn{2}{|c|}{ Con. } & \multicolumn{2}{|c|}{ Org. } & \multicolumn{2}{|c|}{ Con. } \\
\hline & & $\mathrm{E}$ & M & $\mathrm{E}$ & M & E & M & E & M \\
\hline \multirow[t]{4}{*}{1} & 6 Nov. 2015 & 0 & 0 & 0 & 0 & 10 & 14 & 39 & 25 \\
\hline & 13 Nov. 2015 & 0 & 0 & 0 & 0 & 6 & 3 & 7 & 1 \\
\hline & 19 Nov. 2015 & 0 & 0 & 0 & 1 & 6 & 3 & 10 & 1 \\
\hline & 27 Nov. 2015 & 0 & 0 & 0 & 0 & 0 & 0 & 0 & 0 \\
\hline \multirow[t]{2}{*}{2} & 4 Apr. 2016 & 44 & 1,382 & 9 & 73 & 2 & 2 & 7 & 0 \\
\hline & 11 Apr. 2016 & 26 & 355 & 10 & 48 & 5 & 1 & 20 & 0 \\
\hline \multirow[t]{2}{*}{3} & 25 May 2016 & 59 & 1 & 1 & 0 & 3 & 0 & 198 & 2 \\
\hline & 8 June 2016 & 181 & 4 & 0 & 0 & 1 & 4 & 12 & 1 \\
\hline \multirow[t]{4}{*}{4} & 4 July 2016 & 47 & 90 & 4 & 1 & 1 & 1 & 69 & 1 \\
\hline & 11 July 2016 & 108 & 137 & 13 & 10 & 4 & 2 & 70 & 3 \\
\hline & 25 July 2016 & 218 & 311 & 50 & 85 & 34 & 77 & 131 & 72 \\
\hline & 1 Sept. 2016 & 65 & 318 & 53 & 67 & 53 & 137 & 277 & 219 \\
\hline \multirow[t]{2}{*}{5} & 5 Oct. 2016 & 6 & 19 & 15 & 9 & 285 & 266 & 649 & 266 \\
\hline & 12 Oct. 2016 & 34 & 6 & 3 & 4 & 164 & 137 & 239 & 125 \\
\hline Tot. no. & & $788 \mathrm{a}$ & $2,623 b$ & $158 \mathrm{a}$ & $298 b$ & $574 a$ & $647 \mathrm{a}$ & $1,728 \mathrm{a}$ & $716 \mathrm{~b}$ \\
\hline
\end{tabular}



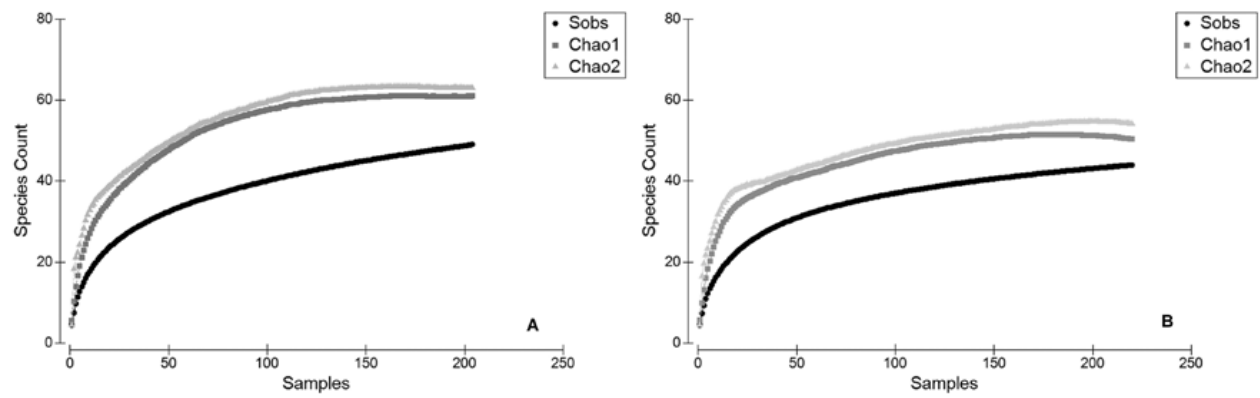

Fig. 2. Rarefaction curves showing observed (Sobs, black line) and estimated species richness using Chao1 (dark gray line) and Chao2 (light gray line) estimators in organic (A) and conventional (B) fields.
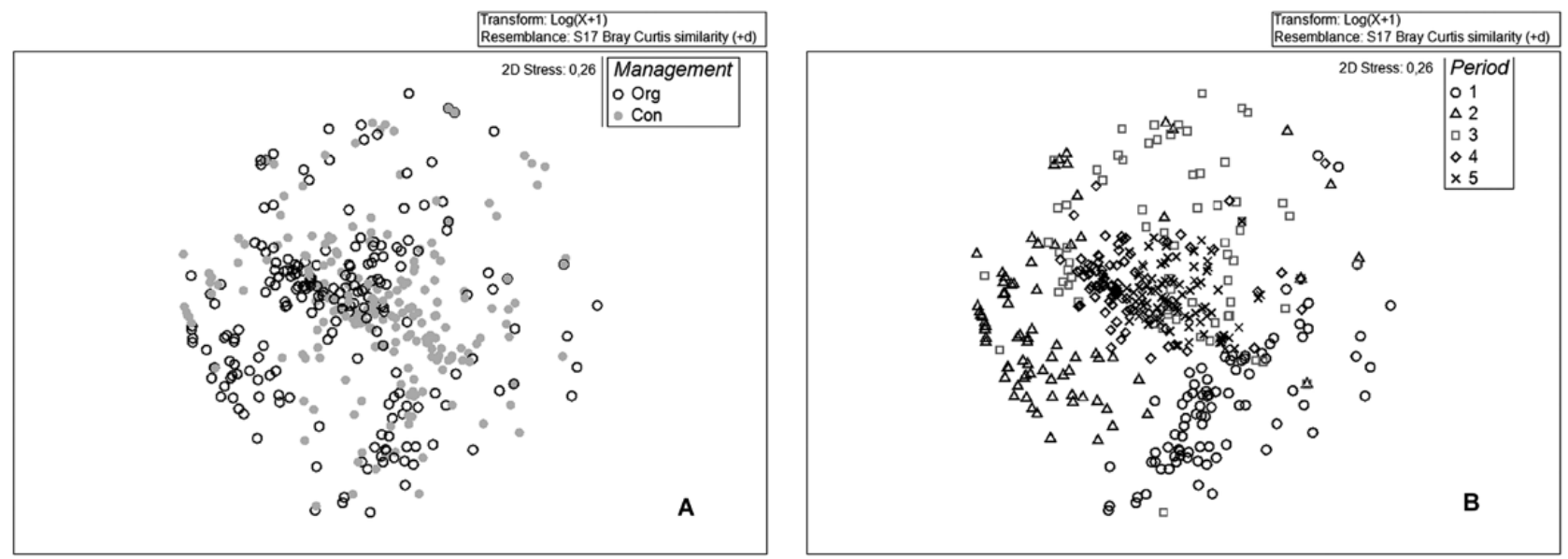

Fig. 3. Nonmetric multidimensional scale analysis. Same symbols in each graph represent samples grouped on the basis of the same factor. (A) Management; (B) sampling period.

conventional ones forming two clouds on the lower-left and on the middle of the graph (Fig. 4A).

The same analysis considering the Tp factor showed two loose clouds with the edge trap samples on the left and the middle trap samples on the right (Fig. 4B). The two outlier samples on the right part of Fig. 4A and B represent a failure of the sampling (due to the accidental loss of traps), which nevertheless did not affect the results of the NMDS ordination as confirmed by Permanova.

The Permanova analysis confirmed this visualization of the samples with significant differences among groups of samples on the basis of the $\operatorname{Mn}(P=0.0001, \mathrm{df}=1$, Unique perms. $=9,922)$ factor as well as the $\operatorname{Tp}(P=0.0027, \mathrm{df}=1$, Unique perms. $=9,936)$ factor with a significant interaction $\mathrm{Mn} \times \mathrm{Tp}(P=0.0001, \mathrm{df}=1$, Unique perms. $=9,938)$. The distribution of the samples was not affected by a nonhomogeneous sample dispersion (deviation from centroid for Mn factor: $F=5.13$; df $1=1$; df $2=30 ; P($ perm $)=0.05$; for $\mathrm{Tp}$ factor: $F=5.13$; df1 $=1 ;$ df2 $=30 ; P($ perm $)=0.05)$.

Based on the significant interaction between the $\mathrm{Mn}$ and $\mathrm{Tp}$ factors, we performed the corresponding pairwise test. In line with the NMDS graph, sample groups from the organic and conventional fields were different both within level Md of factor $\mathrm{Tp}(P=0.0002$; Perm. $=5,072)$ and within level Ed $(P=0.0002$; Perm. $=5,048)$.

Sample groups of the Md and Ed traps were not significant within the level Org $(P=0.18$, Perm. $=5,088)$, but were significantly different within the level Con of the Mn factor $(P=0.0005$; Perm. $=4,998)$. Due to the clear-cut separation of the conventional samples into two clouds (Fig. 4A), we repeated the NMDS analysis by combining the $\mathrm{Mn}$ and $\mathrm{T} \mathbf{p}$ factors. In this case, the conventional samples on the edge compared with those in the middle position were easily distinguishable (Fig. 5). By combining the Mn and Tp factors and recalculating the diversity indexes (Table 4) emerged the important role of the hedgerow in the conventional fields, given that it supported a notably higher number of species and specimens.

\section{SIMPER Analysis}

In the three-factor design, the average Bray-Curtis similarity calculated between all pairs of samples, considering the management system factor, was 24.67 in the organic group and 25.23 in the conventional one (Supp Table 6 [online only]). Pseudoophonus rufipes and P. cupreus together cumulated almost $50 \%$ of the average similarity in organic fields. Pseudoophonus rufipes contributed $23.08 \%$ with the highest ratio similarity/standard deviation $(\mathrm{Sim} / \mathrm{SD}=0.61)$, meaning that this species was well represented and distributed across all samples of the group. Poecilus cupreus had a higher percentage contribution to the average similarity $(25.31 \%)$, however with a lower ratio similarity/standard deviation $(\mathrm{Sim} / \mathrm{SD}=0.53)$, meaning a less homogeneous distribution among samples. Pseudoophonus rufipes and $P$. melas typified the groups of samples in the conventional fields, contributing about $60 \%$ of the average similarity. Pseudoophonus rufipes accounted for $38.52 \%$ and was well distributed among the samples $(\mathrm{Sim} / \mathrm{SD}=0.81)$, whereas $P$. melas accounted for $20.50 \%$ with a ratio Sim/SD of 0.62 .

The same analysis was repeated for the combined factors Mn and Tp in the two-factor design. Poecilus cupreus, P. rufipes, B. immaculicornis, B. crepitans, $N$. brevicollis, and $P$. melas typified both the 


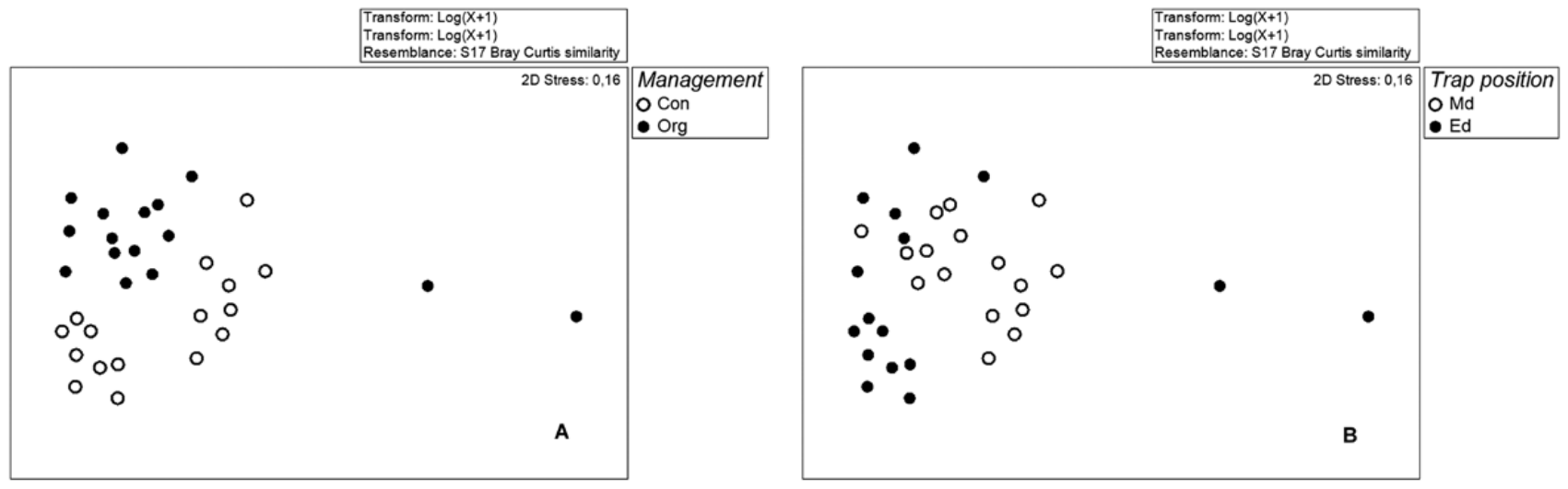

Fig. 4. Nonmetric multidimensional scale analysis. In each graph, the same symbols represent samples grouped on the basis of the same factor. (A) Management; (B) trap position.

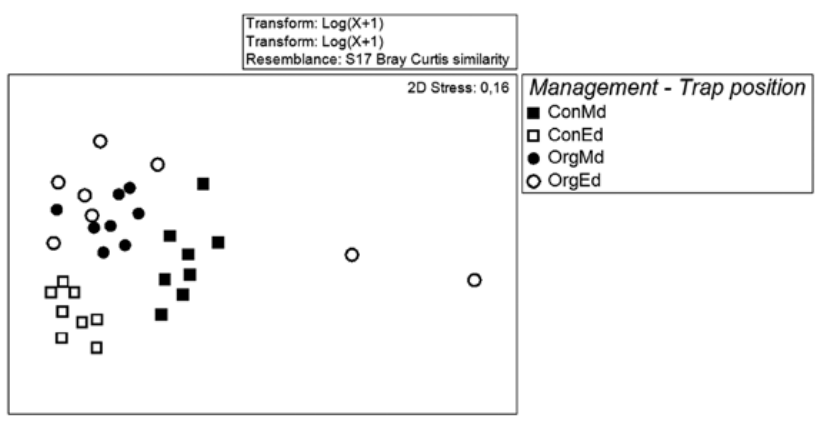

Fig. 5. Nonmetric multidimensional scale analysis carried out on captures simultaneously taking into account management and trap position. ConMd = middle traps in fields with conventional management; ConEd = edge traps in fields with conventional management; OrgMd = middle traps in fields with organic management; OrgEd = edge traps in fields with organic management.

middle and edge traps in the organic fields giving account of about $70 \%$ of average similarity of samples (Supp Table 7 [online only]) without producing separation between the two groups. The species $P$. rufipes, B. immaculicornis, B. crepitans (L.), P. cupreus, and $P$. melas typified the middle trap samples in the conventional fields, whereas the species P. rufipes, P. melas, N. brevicollis (Fabricius), and $P$. niger (Shaller), typified the population of the traps near to the hedges in the same fields. Dissimilarity analysis performed between groups Con-Md and Con-Ed showed that $P$. niger, $P$. melas, N. brevicollis, and C. fuscipes (Göeze) were the species that showed the main percentage contribution to the dissimilarity between the two groups (Supp Table 8 [online only]).

\section{Slugs}

Table 5 shows the total number of slugs captured with the mat traps in the experimental fields and divided according to each sampling period. No slugs were captured in the summer, due to the dry soil conditions. Limacidae resulted the most captured family, whereas significantly less captures were observed for Milacidae and Arionidae.

The slugs were more abundant in the organic fields where the green manure cover made the habitat conditions suitable for slug survival, locomotion, and reproduction until the cover crop has been plowed into the soil (end of April 2016). However, no damage on the vetch-barley cover crop was observed. The correlation between the slug captures and the total number of carabids reached a value of 0.74 . By selecting the most represented species typifying the organic
Table 4. Diversity index calculated by grouping the species by combining the two Mn (management) and Tp (trap position; Md: middle, Ed: edge) factors

\begin{tabular}{lcccc}
\hline Combined factors & $S$ & $N$ & $J$ & $H^{\prime}$ \\
\hline Org-Md & 40 & 4.851 & 0.45 & 1.65 \\
Org-Ed & 35 & 2.468 & 0.59 & 2.09 \\
Con-Md & 33 & 2.413 & 0.55 & 1.93 \\
Con-Ed & 41 & 4.775 & 0.53 & 1.98 \\
\hline
\end{tabular}

$S$ (number of species); $N$ (number of specimens); J' (Pielou's evenness); $H^{\prime}$ (Shannon-Wiener diversity index).

habitat, according to simper analysis, we observed as $P$. cupreus population was the only species showing high correlation $(\delta=0.95)$ with slug abundance (Table 6). In the conventional fields, only six slugs were captured across the sampling periods.

\section{Discussion}

In this work, we investigated the composition of carabid fauna and slug abundance in fields under different management systems, in a long-term agronomic trial carried out near Pisa (Italy).

The carabid abundance was not significantly different under the two management systems. Poecilus cupreus and P. rufipes were the main species captured. This result is consistent with the data collected across Europe by other authors (Porhajašová et al. 2014, Rouabah et al. 2015, Brygadyrenko 2016). These two species have a wide environmental adaptability (Porhajašová et al. 2014) and are considered as typical representatives of the carabid fauna of open habitats and agroecosystems (Tuf et al. 2012, Fusser et al. 2016). The prevalence of both these macropterous species (as most of the captured species) could be related to their better dispersal ability, which makes them suitable in the ecosystems that experience disturbance (Langraf et al. 2017). In particular, organic fields experienced more disturbance as tillage was used for weed control.

The high number of carabid species captured with a very low number of specimens (one or two individuals), suggests that they could play an important role in replacing the loss or reduction of another species with the same functional role (Naeem 1998, Mori et al. 2013). Two species, Asaphidion festivum and Carabus granulatus interstitialis, are included in the regional Red List of Tuscany as rare species or in danger of extinction (Sforzi and Bartolozzi 2001), and both were represented in our samples. In particular, A. festivum (11 specimens) was found only in the organic fields, whereas 18 
Table 5. Slugs trapped in the sampling periods in the two cropping systems

\begin{tabular}{|c|c|c|c|c|c|c|c|c|c|}
\hline \multirow[t]{2}{*}{ Date of samplings } & \multirow[t]{2}{*}{ Period } & \multicolumn{3}{|c|}{ Organic fields } & \multirow[t]{2}{*}{ Tot. no. } & \multicolumn{3}{|c|}{ Conventional fields } & \multirow[t]{2}{*}{ Tot. no. } \\
\hline & & Limacidae & Milacidae & Arionidae & & Limacidae & Milacidae & Arionidae & \\
\hline 6 Nov. 15 & 1 & 0 & 8 & 0 & 8 & 0 & 0 & 0 & 0 \\
\hline 13 Nov. 15 & & 3 & 7 & 5 & 15 & 0 & 0 & 0 & 0 \\
\hline 19 Nov. 15 & & 2 & 10 & 0 & 12 & 0 & 0 & 0 & 0 \\
\hline 27 Nov. 15 & & 0 & 3 & 6 & 9 & 0 & 0 & 0 & 0 \\
\hline 4 Apr. 16 & 2 & 48 & 0 & 9 & 57 & 1 & 0 & 0 & 1 \\
\hline 11 Apr. 16 & & 105 & 1 & 2 & 108 & 0 & 0 & 0 & 0 \\
\hline 25 May 2016 & 3 & 2 & 0 & 1 & 3 & 0 & 0 & 0 & 0 \\
\hline 8 June 2016 & & 0 & 0 & 0 & 0 & 0 & 0 & 0 & 0 \\
\hline 4 July 2016 & 4 & 0 & 0 & 0 & 0 & 0 & 0 & 0 & 0 \\
\hline 11 July 2016 & & 0 & 0 & 0 & 0 & 0 & 0 & 0 & 0 \\
\hline 25 July 2016 & & 0 & 0 & 0 & 0 & 0 & 0 & 0 & 0 \\
\hline 1 Aug. 2016 & & 0 & 0 & 0 & 0 & 0 & 0 & 0 & 0 \\
\hline 5 Sept. 2016 & 5 & 0 & 0 & 0 & 0 & 0 & 1 & 1 & 2 \\
\hline 12 Sept. 2016 & & 0 & 0 & 0 & 0 & 0 & 0 & 0 & 0 \\
\hline Tot. no. & & 160 & 29 & 23 & 212 & 1 & 1 & 1 & 3 \\
\hline
\end{tabular}

Table 6. Pearson correlation among the entire Carabid population and the most abundant Carabid species and slug captures

\begin{tabular}{lccccc}
\hline Carabids Tot. no. & Brachinus crepitans & Poecilus cupreus & Brachinus immaculicornis & Pterostichus melas & Psendoophonus rufipes \\
\hline 0.75 & -0.29 & 0.95 & -0.51 & -0.44 & -0.31 \\
\hline
\end{tabular}

specimens of C. granulatus interstitialis were found in the conventional fields and only three in the organic ones. Their presence suggests the hypothesis of an agroecosystem rich in biodiversity, where also rare species can find enough resources. Rare species could be a positive side effect of the low-input agriculture, prolonged over time in the experimental site, although the stability of their presence has to be confirmed by future samplings.

The Shannon-Wiener index values were a little higher in the conventional than in the organic fields, although the total number of species was higher in the organic than the conventional fields. This difference can be reasonably attributed to the peak in $P$. cupreus, which altered the evenness. In fact, by excluding this species from the $H^{\prime}$ calculation, the index was higher in the organic fields.

Chao1 and Chao 2 indexes estimated a potential to host 10 species more in the organic fields than in the conventional ones suggesting a higher resource availability of organic fields.

Poecilus cupreus is a polyphagous predator, which is also common in arable-ecosystems throughout Europe (Langmaack et al. 2001). It is an iteroparous species, with a spring-summer breeding activity (Matalin 2007). Its biological cycle matched well with our peak of captures. Our data revealed a particular spatial and temporal distribution of this species: the highest number of captures was concentrated in the middle traps of organic fields during the second sampling period. These results are consistent with Thomas et al. (2001), who reported a preferential aggregation of this species in patches within the crop, far from the border with hedgerows. However, they are not in line with the results of Fournier and Loreau (1999) and Rouabah et al. (2015), who prevalently captured this species along the edges of the fields. These discrepancies could be reasonably due to the complexity of the interactions among the factors, which are known to drive the spatial distribution of carabids, and specifically, of $P$. cupreus. In particular, the causes of the opposite results could be sought in the differences between the situations, such as the age of the hedge, the diversity of crops, and the level of input of the management system.
Pseudoophonus rufipes is a common species in European agro-biocenoses with summer-autumn breeding activity. In accordance with Matalin (1997), our captures showed a peak in the autumn and a second, minor peak during the summer samplings. In the conventional fields, the captures mainly occurred in the border traps close to the hedgerows. These results support the findings by Thomas et al. (2001), who trapped carabids in winter cereal fields with hedgerows near Bristol (United Kingdom). In the organic fields, $P$. rufipes captures were lower: we speculate that this occurrence could be due to the higher soil disturbance in these fields during the spring period, whereas the higher presence of weeds in these fields could result in a change of its distribution inside them, being the species zoospermophagous.

The community structure, described by a three-factor design analysis (which takes into account the factor management, period, and trap position), showed that the carabid assemblages were similar in the two management systems, but changed only in relation to time. This evidence was confirmed by the results obtained collapsing the captures of the first two periods and those of the second three periods: again, the comparison between organic and conventional fields did not show any significant difference. These results showed the similarity of the two communities.

However, in the two-factor design, the differences in community structure, due to the management systems, emerged quite clearly. This is reasonably due to an overall view of data obtained by collapsing the time factor: this allowed to highlight the global effect of small differences in each single period.

As regards the influence of hedgerows on captures, the conventional fields showed marked differences in the species composition and quantity of captures, thus highlighting the positive effect of hedges in biodiversity richness. The crucial role of hedgerows as an ecological infrastructure in agroecosystems and their importance in connectivity is well known (Burgio et al. 2015, Sutter et al. 2017). On the opposite, this effect was not observed in the organic fields, probably because of the presence from the autumn to the early spring of an undisturbed green manure cover, which produced a less 
disturbed environment between the border and the middle of the fields. This hypothesis is consistent with the results of Varchola and Dunn (2001) who observed a seasonal movement of carabids from the hedgerow to the inner part of a corn field, with the gradual increase of the ground cover by the plants. The green manure cover reasonably increased the suitable habitat for carabids reducing the spatial competition among species.

According to the SIMPER analysis, P. cupreus and P. rufipes were the most represented species in the organic and conventional fields, respectively. The uneven distribution of $P$. cupreus was highlighted by the lower ratio similarity/standard deviation.

In our study, $P$. niger, $P$. melas, $N$. brevicollis, and C. fuscipes have been found along field edges, in line with other papers (Nazzi et al. 1989, Thomas et al. 2001, Ranjha and Irmler 2014, Rouabah et al. 2015). Such species contributed the highest percentage to the dissimilarity between groups Con-Md and Con-Ed.

The slug assemblage samplings showed that in the organic fields, the population was much more abundant than in the conventional fields. The cover crop reasonably explained this event, although the subsequent dry summer season drastically reduced their mobility. This reduced the potentially negative effects on the following crops as already described in areas with rainy climate, from Vernava et al. (2004) and Snyder et al. (2016). The trend of slug captures have a weak correspondence to the whole carabidofauna sampled in the same periods, but it corresponded with the peak of $P$. cupreus captures observed in the organic fields. Poecilus cupreus is a generalist predator, which includes slug eggs in its diet as showed by Oberholzer and Frank (2003) under lab conditions. Poecilus cupreus is a spring-breeder, and its potential feeding activity on slug eggs may represent an interesting biological controlling factor. The high correlation obtained between slugs trapped and P. cupreus presence in organic fields, even if only with an explorative value, could be consistent with the hypothesis of an ecological response of this species to the presence of slugs in the fields. This has been demonstrated for P. melanarius, which was attracted by the slug chemical cues (McKemey et al. 2004, El-Danasoury and Iglesias-Piñeiro 2018). Further field studies would be necessary to support with certainty the hypothesis of the same attraction on P. cupreus. However, in organic fields, the agroecosystem (and the predators, in particular) seems to have promptly responded to the sudden increase of a potential pest (as the increase of $P$. cupreus population might suggest), probably supported by adjacent habitats, such as hedgerows (Fusser et al. 2016, 2017), which could work as carabid reservoir.

\section{Conclusions}

Our samplings took place in various contiguous fields as part of a long-term agronomic trial, which started in 2001. In this work, we explored the effects of long-term management systems on the carabid assemblage and the slug abundance. Although the sampled fields under the two management systems were close together and the conventional system was not really intensive, we nevertheless noted a difference in carabid assemblages, when the samples were compared without taking into account the sampling period. So the hypothesis of an influence of management on the carabid population emerged confirming the positive role of organic management in terms of biodiversity.

The green manure, beyond its positive agronomic role on soil fertility, represented an important habitat resource for carabids, due to its effects of soil green cover and hosted, at the same time, potentially harmful species as the slugs. However, the richness of agroecosystem biodiversity of predatory species can be a resource to contrast their infestation.
The hedgerows demonstrated their positive role as a biodiversity reservoir in the conventional system, where an overwintering cover crop was grown. This fact confirms the importance of these ecological infrastructures in carabid conservation and their role in supporting ecosystem services.

Finally, our data support once more, the reliability and suitability of carabids as sensitive bioindicators also at local scale.

\section{Supplementary Data}

Supplementary data are available at Environmental Entomology online.

Supp Table S1. List of Carabids captured in pitfall traps: dominance values (Dom) are calculated according to Tischler (1949); Org: captures in organic fields; Con: Captures in conventional fields; Seas. breed (season breeding: Spr, spring; Aut: autumn); Diet, Z: zoophagous; S: spermophagous; ZS: zoospermophagous); Wings, M: macropterous, B: brachipterous; P: pteridimorphic; chorotypes (Chor) were defined according to Vigna Taglianti (2005).

Supp Table S2. Shannon-Wiener diversity and Pielou's evenness indexes for captures in the organic and conventional fields, calculated excluding data on Poecilus cupreus.

Supp Table S3. Estimates of components of variation on the three-factor mixed design (Pe, random factor).

Supp Table S4. Periods 1 and 2: Permanova analysis carried out on data of captures in the fields under organic and conventional management systems during the first two sampling periods.

Supp Table S5. Periods 3, 4, and 5: Permanova analysis carried out on data of captures in the fields under organic and conventional management systems during the sampling periods 3,4 , and 5 .

Supp Table S6. Similarity percentages-species contribution. Factor group: Mn, management.

Supp Table S7. Similarity percentages-species contribution factor group combined: type of management (Mn: Con, Org) and trap position (Tp: Md, Ed).

Supp Table S8. Dissimilarity percentages-species contribution factor group combined: management and trap position factors.

\section{Acknowledgments}

The authors wish to thank the Ministero delle Politiche Agricole Alimentari e Forestali (MiPAAF) and the FP7-ERA-Net CORE Organic Plus consortium, which financed the project FERTILCROP (2014-2017), thus enabling this work to be carried out. The authors also wish to thank the field and lab staff of the Centre for Agro-Environmental Research 'Enrico Avanzi', University of Pisa, who provided technical and logistical support, managed the experimental site, and helped in the sample processing. The authors are grateful to the reviewers for their excellent revision, which strongly improved the manuscript.

\section{References Cited}

Albertini, A., R. Pizzolotto, and R. Petacchi. 2017. Carabid patterns in olive orchards and woody-semi-natural habitat: first implications for conservations biological control against Bactrocera oleae. BioControl 62: 71-83.

Anderson, M. J., R. N. Gorley, and K. R. Clarke. 2008. Permanova + for Primer: guide to software and statistical methods. PRIMER-E, Plymouth, United Kingdom.

Bàrberi, P., and M. Mazzoncini. 2006. The MASCOT (Mediterranean Arable Systems COmparison Trial) long-term experiment (Pisa, Italy), pp. 1-14. In J. Raupp, C. Pekrun, M. Oltmanns and U. Köpke, (eds.) Long-term field experiments in organic farming. ISOFAR Scientific Series, Verlag, Berlin (DE).

Basualdo, C. V. 2011. Choosing the best non-parametric richness estimator for benthic macroinvertebrates databases. Rev. Soc. Entomol. Argent. 70: 27-38. 
Bohan, D. A., A. C. Bohan, D. M. Gleen, W. O. C. Symondson, C. W. Wiltshire, and L. Hughes. 2000. Spatial dynamics of predation by carabid beetles on slugs. J. Anim. Ecol. 69: 367-379.

Brandmayr, P., T. Zetto, and R. Pizzolotto. 2005. Coleotteri Carabidi per la valutazione ambientale e la conservazione della biodiversità. Manuale operative, vol. 34, pp. 151-185. APAT, Roma, Italy.

Brygadyrenko, V. V. 2016. Evaluation of ecological niches of abundant species of Poecilus and Pterostichus (Coleoptera: Carabidae) in forests of steppe zone of Ukraine. Entomol. Fenn. 27: 81-100.

Burgio, G., D. Sommaggio, M. Marini, G. Puppi, A. Chiarucci, S. Landi, R. Fabbri, F. Pesarini, M. Genghini, R. Ferrari, et al. 2015. The influence of vegetation and landscape structural connectivity on butterflies (Lepidoptera: Papilionoidea and Hesperiidae), Carabids (Coleoptera: Carabidae), Syrphids (Diptera: Syrphidae), and Sawflies (Hymenoptera: Symphyta) in Northern Italy Farmland. Environ. Entomol. 44: 1299-1307.

Cameron, R. A. D., N. B. Jackson, and B. Eversham. 1983. A field key to the slugs of the British Isles. Field Studies J. 5: 807-824.

Chao, A., and C. H. Chiu. 2016. Nonparametric estimation and comparison of species richness, pp. 1-11. In eLS (ed.). John Wiley \& Sons, Ltd, Chichester, United Kingdom.

Ciaccia, C., F. Ceglie, F. Tittarelli, D. Antichi, S. Carlesi, E. Testani, and S. Canali. 2017. Green manure and compost effects on N-P dynamics in Mediterranean organic stockless systems. J. Soil Sci. Plant Nutr. 17: 751-769.

Clarke, K. R., and R. M. Warwick. 2001. Change in marine communities: an approach to statistical analysis and interpretation, 2nd ed. Primer-E, Plymouth, United Kingdom.

Douglas, M. R., and J. F. Tooker. 2012. Slug (Mollusca: Agriolimacidae, Arionidae) ecology and management in no-till field crops, with an emphasis on the mid-Atlantic region. J. Integr. Pest Manag. 3: C1-C9.

El-Danasoury, H., and J. Iglesias-Piñeiro. 2018. Predation by polyphagous carabid beetles on eggs of a pest slug: potential implications of climate change. J. Appl. Entomol. 142: 340-348.

Fournier, E., and M. Loreau. 1999. Effects of newly planted hedges on ground-beetle diversity (Coleoptera, Carabidae) in an agricultural landscape. Ecography 22: 87-97.

Fusser, M. S., S. C. Pfister, M. H. Entling, and J. Schirmel. 2016. Effects of landscape composition on carabids and slugs in herbaceous and woody field margins. Agric. Ecosyst. Environ. 226: 79-87.

Fusser, M. S., S. C. Pfister, M. H. Entling, and J. Schirmel. 2017. Effects of field margin type and landscape composition on predatory carabids and slugs in wheat fields. Agric. Ecosyst. Environ. 247: 182-188.

Gobbi, M., and D. Fontaneto. 2008. Biodiversity of ground beetles (Coleoptera: Carabidae) in different habitats of the Italian Po lowland. Agric. Ecosyst. Environ. 127: 273-276.

Gomiero, T., D. Pimentel, and M. G. Paoletti. 2011. Environmental impact of different agricultural management practices: conventional vs. organic agriculture. Crit. Rev. Plant Sci. 30: 95-124.

Holland, J. M. 2002. Carabid beetles: their ecology, survival and use in agroecosystems, pp. 1-40. In J. M. Hooland (ed.), The agroecology of Carabid beetles. Intercept Publication, Andover, MA.

Holland, J. M., and M. L. Luff. 2000. The effects of agricultural practices on Carabidae in temperate agroecosystems. Integr. Pest Manage. Rev. 5: 109-129.

Howlett, S. A. 2012. Terrestrial slug problems: classical biological control and beyond. CAB Rev. 7: 1-10

Kotze, D. J., P. Brandmayr, A. Casale, E. Dauffy-Richard, W. Dekoninck, M. J. Koivula, G. L. Lövei, D. Mossakowski, J. Noordijk, W. Paarmann, et al. 2011. Forty years of carabid beetle research in Europe - from taxonomy, biology, ecology and population studies to bioindication, habitat assessment and conservation. ZooKeys 100: 55-148.

Kromp, B. 1989. Carabid beetle communities (Carabidae, Coleoptera) in biologically and conventionally farmed agroecosystems. Agric. Ecosyst. Environ. 27: 241-251

Langmaack, M., S. Land, and W. Büchs. 2001. Effects of different field management systems on the carabid coenosis in oil seed rape with special respect to ecology and nutritional status of predacious Poecilus cupreus L. (Col., Carabidae). J. Appl. Entomol. 125: 313-320.

Langraf, V., K. Petrovičová, S. David, M. Ábelová, and J. Schlarmannová. 2017. Body volume in ground beetles (Carabidae) reflects biotope disturbance. Folia Oecol. 44: 114-120.

Legrand, A., C. Gaucherel, J. Baudry, and J. M. Meynard. 2011. Long-term effects of organic, conventional, and integrated crop systems on Carabids. Agron. Sust. Dev. 31: 515-524.

Lemic, D., M. Čačija, H. Virić Gašparić, Z. Drmić, R. Bažok, and I. Pajač Živković. 2017. The ground beetle (Coleoptera: Carabidae) community in an intensively managed agricultural landscape. Appl. Ecol. Environ. Res. J. 15: 661-674.

Luff, M. L. 1982. Population dynamics of Carabidae. Ann. Appl. Biol. 101: 164-170.

Magurran, A. E. 1988. Ecological diversity and its measurement. Princeton University Press, Princeton, NJ.

Matalin, A. V. 1997. Specific features of life cycle of Pseudoophonus (s.str.) rufipes Deg. (Coleoptera, Carabidae) in the Southwestern Moldova, Izv. Akad. Nauk. Ser. Biol. 4: 455-466

Matalin, A. V. 2007. Typology of life cycles of ground beetles (Coleoptera Carabidae) from western Palaearctic. Zool. Zh. 86: 1196-1220.

Mazzoncini, M., S. Canali, M. Giovannetti, M. Castagnoli, F. Tittarelli, D. Antichi, R. Nannelli, C. Cristani, and P. Barberi. 2010. Comparison of organic and conventional stockless arable systems: a multidisciplinary approach to soil quality evaluation. Appl. Soil Ecol. 44: 124-132.

Mazzoncini, M., D. Antichi, N. Silvestri, G. Ciantelli, and C. Sgherri. 2015 Organically vs conventionally grown winter wheat: effects on grain yield, technological quality, and on phenolic composition and antioxidant properties of bran and refined flour. Food Chem. 175: 445-451.

McKemey, A. R., D. M. Glen, and W. O. C. Symondson. 2004. How does a carabid predator find aggregations of slugs in the field? Electroantennograms and behavioural assays suggest chemical cues. Bull. Entomol. Res. 94: 235-244.

Mendiburu, F. D. 2015. Agricolae: Statistical procedures for agricultural research R package version 1.2-3. http://CRAN.R- project.org/package=agricolae

Mori, A. S., T. Furukawal, and T. Sasaki. 2013. Response diversity determines the resilience of ecosystems to environmental change. Biol. Rev. 88 349-364.

Naeem, S. 1998. Species redundancy and ecosystem reliability. Conserv. Biol. 12: 39-45.

Nazzi, F., M. G. Paoletti, and G. G. Lorenzoni. 1989. Invertebrate dynamics of soybean agroecosystems encircled or not by hedgerows in Friuli, Italy. First Data. Agric. Ecosyst. Environ. 27: 1-4.

Oberholzer, F., and T. Frank. 2003. Predation by the Carabid beetles Pterostichus melanarius and Poecilus cupreus on slugs and slug eggs. Biocontrol Sci. Techn. 13: 99-110.

Pesarini, C., and V. Monzini. 2010. Insetti della fauna italiana. Coleotteri Carabidi I. Natura 100: 3-152.

Pesarini, C., and V. Monzini. 2011. Insetti della fauna italiana. Coleotteri Carabidi II. Natura 101: 3-144.

Pizzolotto, R., A. Mazzei, T. Bonacci, S. Scalercio, N. Iannotta, and P. Brandmayr. 2018. Ground beetles in Mediterranean olive agroecosystems: their significance and functional role as bioindicators (Coleoptera, Carabidae). PLoS One 13: e0194551.

Porhajašová, J., A. Rakovská, J. Noskovič, M. Babošová, and T. Čeryová. 2014. Influence of agroecosystems on biodiversity of Carabidae in the nature reserve of Alúvium Žitavy in the southwestern part of the Slovak Republic. Res. J. Agric. Sci. 46: 283-289.

Preacher, K. J. 2001. Calculation for the chi-square test: an interactive calculation tool for chi-square tests of goodness of fit and independence. (http:// quantpsy.org) (accessed August 2019).

Purtauf, T., I. Roschewitz, J. Dauber, C. Thies, T. Tscharntke, and V. Wolters. 2005. Landscape context of organic and conventional farms: influences on carabid beetle diversity. Agric. Ecosyst. Environ. 108: 165-174.

Ranjha, M., and U. Irmler. 2014. Movement of carabids from grassy strips to crop land in organic agriculture. J. Insect Conserv. 18: 457-467.

Rouabah, A., J. Villard, B. Amiaud, S. Plantureux, and F. Lasserre-Joulin. 2015. Response of Carabid beetles diversity and size distribution to the 
vegetation structure within differently managed field margins. Agric. Ecosyst. Environ. 200: 21-32.

Santini, L. 2000. Molluschi Gasteropodi. Cap. 5, pp. 145-153. In B. Baccetti, S. Barbagallo, L. Suss, and E. Trembaly (eds.), Manuale di Zoologia Agraria. Antonio Delfino Publication, Roma, Italy.

Sforzi, A., and L. Bartolozzi. 2001. Libro Rosso degli insetti della Toscana. ARSIA, Agenzia Regionale per lo Sviluppo e l'Innovazione nel settore Agricolo-forestale. Pub. EFFEEMME LITO, Firenze, Italy, 375 pp.

Shearin, A. F., S. C. Reberg-Horton, and E. R. Gallandt. 2007. Direct effects of tillage on the activity density of ground beetle (Coleoptera: Carabidae) weed seed predators. Environ. Entomol. 36: 1140-1146.

Shearin, A. F., S. C. Reberg-Horton, and E. R. Gallandt. 2008. Cover crop effects on the activity-density of the weed seed predator Harpalus rufipes (Coleoptera: Carabidae). Weed Sci. 56: 442-450.

Snyder, E. M., H. D. Karsten, W. S. Curran, G. M. Malcolm, and J. Hyde. 2016. Green manure comparison between winter wheat and corn: weeds, yields, and economics. Agron. J. 108: 1-11.

Sutter, L., M. Albrecht, and P. Jeanneret. 2017. Landscape greening and local creation of wildflower strips and hedgerows promote multiple ecosystem services. J. Appl. Ecol. 55: 612-620.
Thomas, C. F. G., L. Parkinson, G. J. K. Griffiths, A. F. Garcia, and E. J. P. Marshall. 2001. Aggregation and temporal stability of carabid beetle distributions in field and hedgerow habitats. J. Appl. Ecol. 38: 100-116.

Tischler, W. 1949. Grundzüge der terrestrischen Tierökologie. Vieweg Verl., Braunschweig, Deutschland, Germany, 219 pp.

Tuf, I. H., P. Dedek, and M. Veselý. 2012. Does the diurnal activity pattern of carabid beetles depend on season, ground temperature and habitat? Arch. Biol. Sci. 64: 721-732.

Varchola, J. M., and J. P. Dunn. 2001. Influence of hedgerow and grassy field borders on ground beetle (Coleoptera: Carabidae) activity in fields of corn. Agric. Ecosyst. Environ. 83: 153-163.

Vernava, M. N., P. M. Phillips-Aalten, L. A. Hughes, H. Rowcliffe, C. W. Wiltshire, and D. M. Glen. 2004. Influences of preceding cover crops onslug damage and biological control using Phasmarhabditis hermaphrodita. Ann. Appl. Biol. 145: 279-284.

Vigna Taglianti, A. 2005. Checklist e corotipi di Carabidi della fauna italiana. Appendice B, pp. 186-225. In P. Brandmayr, T. Zetto, and R. Pizzolotto (eds.), Coleotteri Carabidi per la valutazione ambientale e la conservazione della biodiversità. Manuale operative. APAT, Roma, Italy, 34. 